\title{
A IMPORTÂNCIA DA CONTAÇÃO DE HISTÓRIA S COMO FERRAMENTA PEDAGÓGICA NA EDUCAÇÃO INFANTIL
}

\author{
https://dx.doi.org/10.48097/2674-8673.2021n4p05
}

\author{
Fábia Teixeira Farias ${ }^{1}$ \\ Fabiana Maria da Silva ${ }^{2}$
}

\begin{abstract}
RESUMO
O presente trabalho faz um estudo sobre a contação de histórias na educação infantil como ferramenta pedagógica. A pesquisa bibliográfica foi realizada por meio de sites especializados como Scielo e outros. A partir do referencial teórico, conceitos e análises realizadas chegou-se à conclusão que a contação de histórias favorece a aprendizagem, principalmente no desenvolvimento da socialização, comunicação e aprendizagem dos estudantes, criando infinitas possibilidades pedagógicas.
\end{abstract}

Palavras-chave: Educação infantil. Literatura. Contação de histórias.

Data de submissão: 22/09/2020

Data de aprovação: 12/11/2020

\begin{abstract}
The present work makes a study on the storytelling in early childhood education as a pedagogical tool. The bibliographic research was carried out through specialized sites such as Scielo and others. Based on the theoretical framework, concepts and analyzes carried out, it was concluded that storytelling favors learning mainly in the development of socialization, communication and student learning, creating infinite pedagogical possibilities.
\end{abstract}

Keywords: Early childhood education. Literature. Storytelling.

\section{INTRODUÇ̃̃̃O}

Este trabalho tem a finalidade de analisar a contação de histórias na educação infantil como ferramenta para desenvolver o processo de socialização. O interesse pelo tema surgiu após um estágio supervisionado e, desde então, se manteve como foco de pesquisas.

\footnotetext{
${ }^{1}$ Discente do curso de Licenciatura em Pedagogia da Faculdade Metropolitana da Grande Recife. E-mail: fatimafteixeira@gmail.com

${ }^{2}$ Orientadora. Docente do curso de Pedagogia da Faculdade Metropolitana da Grande Recife.

E-mail: fabiana.silva1@gmail.com
} 
A contação de histórias é uma prática muito antiga. Desde muito tempo o homem usa a comunicação verbal e as histórias para transmitir sua cultura às gerações mais novas. Em relação à educação, ela é indicada na infância como um importante auxílio à prática pedagógica, pois está relacionada com outros modos de expressão, que também podem ser desenvolvidos nessa fase, como o movimento, a imagem e a música, que vão formar a bagagem comunicativa da criança desde os seus primeiros anos.

O professor, ao iniciar uma história, pode estabelecer com a criança um ambiente de cumplicidade, estimulando a imaginação, a criatividade, a oralidade, o gosto pela leitura, e ainda contribuindo na formação da personalidade desta criança, envolvendo-a afetivamente e socialmente. Além disso, esta atividade pode também aproximar a criança do mundo das palavras, ou seja, da escrita e da leitura. Ao contar histórias para as crianças na educação infantil, o professor consegue proporcionar momentos com atitudes positivas, contemplando a formação de posturas e habilidades que irão permitir maior estímulo à leitura da criança.

Ao contar histórias para uma criança temos a oportunidade de compartilhar emoções, o prazer de escutar, e a convivência em grupo. Nesses momentos a literatura também passa a ser valorizada. Histórias, fábulas, contos, são gêneros que, em geral, fazem parte dessa atividade, o que pode favorecer o prazer pela leitura de uma diversidade de temas, autores e estilos. Muitos estudos apontam que a contação de histórias é um recurso muito importante para o planejamento dos professores na área da educação infantil, e serve como recurso para envolver as crianças em múltiplas atividades, citando como exemplo, o ouvir, opinar, indagar e ao mesmo tempo se expressar.

A presente análise poderá servir como uma das ferramentas que vai contribuir para a classe de professores que trabalha com a educação infantil, sendo, por vezes, introduzida no cotidiano de cada criança. A contação de histórias na educação infantil desperta a curiosidade, estimula a imaginação, desenvolve a autonomia e o pensamento crítico da criança, proporcionando vivenciar diversas emoções como medo e angústias, ajudando a resolver seus conflitos emocionais, aliviando sobrecargas emocionais próprias de cada um.

\section{FUNDAMENTAÇÃO TEÓRICA}

Os autores pesquisados afirmam que a contação de histórias é uma ferramenta que visibiliza o interesse pela leitura, ajuda no desenvolvimento psicológico e moral, auxiliando 
na manutenção da saúde mental das crianças em fase de desenvolvimento, ampliando o vocabulário e o mundo de ideias, além de desenvolver a linguagem e o pensamento.

Ainda trabalha a atenção, a memória e a reflexão. Desperta a sensibilidade, a descoberta da identidade, adapta as crianças ao meio ambiente, assim como desenvolve as funções cognitivas para o pensamento como comparação, raciocínio lógico, pensamento hipotético convergente e divergente.

\section{As muitas contribuições da contação de histórias na educação infantil}

Quando os professores, na sala de aula ou em uma roda de conversa, começam a contar histórias podem vivenciar como as crianças interagem nesse momento. Daí eles observam e analisam como esta prática pode acrescentar diversos valores no momento em que ela está sendo realizada.

Alega-se que o comportamento das crianças ao escutarem uma história é de ficarem atentas às explicações e o silêncio pode ser quebrado a qualquer momento com perguntas por parte do grupo. A contação de histórias na educação infantil preenche o trabalho dos professores com as crianças naquele momento. Há a possibilidade de se poder trabalhar com diversos materiais de pintura: o lápis de cor, o de cera, e outros materiais que estiverem à disposição.

Depois que a atividade acaba ainda se pode pedir para que cada criança risque no papel o que mais gostou na história contada. Com isso se incentiva a criança a desenhar, imaginar ou fantasiar a história apresentada naquela ocasião. O tema desse trabalho privilegia apresentar a contação de histórias como ferramenta de conhecimentos, de estímulos e de ideias, auxiliando a área da educação infantil, apontando os mais distintos modos de apoio e servindo ao mesmo tempo como aprendizado desses professores.

Segundo Rodrigues (2005):

[...] A contação de histórias nas escolas vem sendo muito utilizada no universo da educação infantil e no início do Ensino Fundamental. É uma atividade própria de incentivo à imaginação e o trânsito entre o fictício e o real. Ao preparar uma história para ser contada, tomamos a experiência do narrador e de cada personagem como nossa e ampliamos nossa experiência vivencial por meio da narrativa do autor. Os fatos, as cenas e os contextos são do plano do imaginário, mas os sentimentos e as emoções transcendem a ficção e se materializam na vida real. (RODRIGUES, 2005, p. 4).

Ainda a respeito da temática, Rodrigues (2005) diz que:

[...] Cada criança precisa ser vista como ser único, e que passa por estágios psicológicos durante todo o seu desenvolvimento, precisando assim ser 
observados acima de tudo respeitado pelos adultos, e essas etapas vão sempre depender da idade e do nível de conhecimento, no domínio dos mecanismos leitura e o nível de amadurecimento psíquico, afetivo e intelectual. (RODRIGUES, 2005, p. 4).

Rodrigues (2005) ainda faz uma ressalva:

[...] Todos estes pontos precisam ser levados em conta no momento da escolha da história a ser contada, e perceber que o contato com as histórias gradativamente iria aumentar o gosto e o prazer por esta atividade e a probabilidade dela tornar-se um adulto que gosta de ler um bom livro. A contação de histórias desperta na criança o seu desenvolvimento psíquico na construção dos significados das palavras ouvidas, de forma que incorporadas ao contexto da história, possam, além de enriquecer o seu vocabulário, auxiliar no desenvolvimento da leitura e da escrita. (RODRIGUES, 2005, p. 11).

Partindo das afirmativas vindas por meio das citações que se empregam no trabalho sobre a contação de histórias, reforça-se que a mesma promove estímulos à leitura na educação infantil, uma vez que sonhar, imaginar e sentir são contribuições essenciais nesse processo em que a criança está em formação.

Farias (2012) nos ensina que há três níveis de leitura: o primeiro é o tato, o prazer de tocar o livro com o papel agradável, com ilustrações, figuras e planejamento gráfico caprichado; o segundo é o emocional, aquele em que a fantasia e a liberdade das emoções mostram o que ele faz e o que provoca em nós; o terceiro nível é o racional, ligado à autoria, ao plano intelectual da leitura. As contribuições de uma contação de histórias são distinguidas como um importante auxiliar na formação das crianças, na compreensão e absorção dos significados, assim como no desenvolvimento das práticas leitoras.

As crianças que escutam as histórias incorporam uma atitude analítica exemplificada pelo orador, por meio de seus comentários e problematizações durante a contação, permitindo o desenvolvimento do seu senso crítico e permitindo o convívio em grupo com mais respeito por parte de seus coleguinhas.

Sabe-se que as histórias têm o poder de transformar e acrescentar valores, além de permitir que os conhecimentos na aprendizagem da criança se ampliem e agreguem muitos valores. É preciso compartilhar ideias na medida em que ajudem a estruturar as funções motoras, sensoriais, simbólicas, lúdicas e relacionais da criança. Também é importante na contacão de histórias desenvolver na criança o sentido de observar, categorizar, escolher e propor. 
A aquisição de habilidades linguísticas como produzir e compreender histórias tem consequências importantes em quase todos os aspectos da vida de uma criança, incluindo interações positivas com seus pares, comunicação eficiente e aprendizagem adequada na escola. (SPENCER, 2010).

Bettelheim (2009) afirma que a história realmente prende a atenção das crianças, devendo entretê-las e despertar a curiosidade. Deve-se estimular a imaginação, ajudando-as a desenvolver seu intelecto e a tornar claras suas emoções, ansiedades e aspirações, percebendo suas dificuldades e, ao mesmo tempo, sugerindo soluções para os problemas que as perturbam.

\section{Aspectos históricos da contação de histórias na educação infantil}

Resgatar um pouco do contexto histórico da contação de histórias nos remete a lembranças da infância, quando ouvíamos histórias contadas por adultos em muitos momentos, na escola, na rua, no ambiente familiar. O riso, o susto e alegrias faziam parte daquele momento. A contação de história faz parte da tradição oral da humanidade e permeia diversos gêneros textuais.

A fábula, por exemplo, é um gênero literário cuja característica principal é a narração alegórica, fantasiosa, sem compromisso com a realidade, mas permeada por recursos lúdicos e pedagógicos. É uma narrativa breve que sempre leva a um ensinamento porque a moralidade a distingue dos demais gêneros literários. (COELHO, 1986). Outro gênero que também faz parte da tradição oral e está no imaginário popular é a cantiga de roda e que também nos remete a lembranças de um cotidiano que não parece ter muito tempo.

Coelho (1986) afirma que a história é como um recurso que a humanidade buscou desenvolver como um instrumento para propagar informações. Cada cultura tem seu estoque de narrativas que são originárias ou não daquela cultura, mas que tem o objetivo fundamental de atingir as preocupações que estão, por natureza, ligadas a todo ser humano.

Mesmo com os grandes avanços tecnológicos da modernidade ainda existem culturas que procuram guardar (armazenar) e depois repassar seus conhecimentos fazendo uso de suas memórias através da oralidade.

[...] Nos dias atuais pode-se até pensar que os contadores de histórias são peças de uma era remota, alguém ou algo que ficou no passado, mas não é bem assim, porque em algum momento uma ou várias pessoas poderão fazer o uso da contação de histórias, todos tem essas capacidades e até mesmo por assim dizer um dom de relatar para outras pessoas suas experiências, conselhos, receitas, 
poemas e até mesmo canções, sem ao menos perceber que tudo isso, seja um ato simples de contar histórias, é gostar de acalentar sonhos como se os mesmos pudessem ser reais. (BUSSATTO, 2006, p. 10-11).

Um aspecto interessante sobre a tradição oral é que em cada época e contexto o contador apresenta traços diferentes das histórias. Um exemplo disso no contexto brasileiro são as histórias folclóricas implantadas em cada região.

\section{Conjecturas sobre a contação de história na BNCC}

A Base Nacional Comum Curricular (BNCC) é um documento normativo de referência obrigatória que orienta as redes de ensino em relação à elaboração de currículos e propostas pedagógicas. Dada essa importância, é interessante para essa pesquisa analisar a contação de histórias na educação infantil a partir da BNCC.

Antes, é importante mencionar que a organização curricular da BNCC para a educação infantil está estrutura em cinco campos de experiências. A partir deles são definidos os objetivos de aprendizagem: o eu, o outro e o nós; corpo, gestos e movimentos; traços, sons, cores e formas; escuta, fala, pensamento e imaginação; espaços, tempos, quantidades, relações e transformações. (MEC, 2019).

É importante, ainda, destacar os direitos de aprendizagem: brincar, conhecer-se, conviver, explorar, expressar-se e participar. São esses direitos que asseguram as condições para que as crianças "aprendam em situações nas quais possam desempenhar um papel ativo em ambientes que as convidem a vivenciar desafios e a sentirem-se provocadas e resolve-los, nas quais possam construir significados sobre si, os outros e o mundo social e natural" (MEC, 2019).

Os estudos não apontam a orientação da BNCC em relação à contação de histórias na educação infantil, no entanto, é possível associar seus objetivos de aprendizagens a este trabalho. Apesar de não se encontrar na BNCC, no âmbito da educação infantil, os termos "contação de histórias", foram encontrados, algumas vezes, os termos "literatura infantil" e a valorização de diversos gêneros para ajudar na construção das habilidades propostas.

\section{A contação de histórias como prática pedagógica}

Como prática pedagógica a contação de histórias favorece de forma significativa a prática docente em salas de educação infantil. Ao ter contato com histórias que estão sendo contadas pelos professores, os alunos, consequentemente, recebem estímulos que aguçam a 
própria imaginação. Além de educar, instruir e, por conseguinte, desenvolver habilidades cognitivas, a contação de histórias auxilia no processo de aquisição da leitura e da escrita e, acima de tudo, pode se dizer que é uma atividade interativa que potencializa a oralidade infantil. (BUSSATO, 2006). Segundo o autor:

[...] As histórias são verdadeiras fontes de sabedoria, que tem papel formador da identidade. Há pouco tempo, elas foram redescobertas como fonte de conhecimento de vida, tornando-se também um grande recurso para educadores. Com o advento da comunicação, ampliação dos recursos e globalização das informações, a linguagem falada tende a definhar, porém, concomitante a esse desenvolvimento, surgiu uma necessidade de resgatar os valores tradicionais e a própria natureza humana. A tradição oral dos contos, não só apareceu, como está ganhando força nos últimos tempos. (BUSSATTO, 2006, p. 21).

A ludicidade, em conjunto com a contribuição da contação de histórias no processo da aprendizagem, envolve principalmente a responsabilidade, autonomia, e também a autoexpressão, fazendo com que a criança sinta-se incentivada e estimulada, construindo seus conhecimentos sobre ela mesma e sobre o mundo no qual está inserida, de forma autônoma.

As práticas pedagógicas devem se estruturar como instâncias críticas das práticas educativas, na perspectiva de transformação coletiva dos sentidos e significados das aprendizagens. A esse respeito, Bussato (2206) afirma que:

[...] Na contacão de histórias a prática pedagógica deve ser mais envolvente, porque contar histórias mobiliza o imaginário, permitindo vivência de tempos e lugares distintos. É uma viagem sem sair do lugar! As oportunidades criadas pelas narrativas podem ser infinitamente variadas, despertando emoções, ampliando conhecimentos, exercitando formas de interagir e oportunizar a prática da alteridade. (BUSSATTO, 2006, p. 22).

Quando um ouvinte se identifica com determinado personagem de uma história e acaba por se colocar no lugar daquele papel, exercita sua alteridade, uma vez que pode entender o ponto de vista de outra pessoa, às vezes, contrário do seu, quase sempre diferente.

Ainda em relação à prática pedagógica, Sisto (2005) completa:

[...] Como prática pedagógica a história se incorpora à reflexão contínua e coletiva. Como exemplo: uma aula ou um encontro educativo se torna uma prática pedagógica quando se organiza em torno de intencionalidades. Será pedagógica à medida que buscar a construção de práticas que garantam os encaminhamentos propostos pelas intencionalidades que possam ser realizadas e a proposta disponibilizada a todos. (SISTO, 2005, p. 17).

Quando se fala em prática pedagógica, em relação a contar histórias, nos referimos a algo além da prática didática, pois as práticas pedagógicas devem ser estruturadas como 
instâncias críticas das práticas educativas, nas perspectivas de transformação coletiva dos sentidos e significados das aprendizagens.

A criança sonha e o professor passa a ser coadjuvante nesse processo de encantar, em fazer com que cada criança possua seu mundo imaginário. Cada história traz um relato fictício, mas na imaginação da criança a história suaviza cada momento e o professor passa a reger essa orquestra que deve ser regida com muito amor e dedicação.

A esse respeito, Patrini (2005) relata:

[...] $\mathrm{O}$ ato de contar histórias é uma ferramenta que não incentiva somente a imaginação, mas favorece o hábito pela leitura e, ao mesmo tempo, amplia o vocabulário, a narrativa, e a cultura. É um passeio imaginativo. Contar histórias é uma arte que pode ser feita de várias maneiras onde o professor pode usar da sua imaginação e dos recursos que estiverem ao seu alcance, porque nem sempre dispõe de materiais. Diante disso deve-se improvisar na forma de narrar. (PATRINI, 2005, p. 143).

A contação de histórias como prática pedagógica mostra que a criança pode ter uma compreensão mais aberta do mundo em que vive, na dimensão que a história contada vai permitir a compreensão mais eficiente daquele momento, com diversas formas de expressão como o movimento, a imagem e a música, formando a bagagem comunicativa da criança. A importância da contação de histórias nas escolas se deve ao fato de ela proporcionar o desenvolvimento completo da criança, buscando ampliar o fortalecimento da autoestima, além da função lúdica, da criação e da vontade de ler e escrever, uma vez que o espaço escolar é visto como um lugar de construção, reconstrução e inovação dos conhecimentos.

\section{METODOLOGIA}

A referida pesquisa é de abordagem qualitativa e, com técnicas de coleta de dados, opta por uma pesquisa bibliográfica. A pesquisa foi realizada em duas etapas. Na primeira foi realizada a busca por trabalhos que abordassem o tema. Foram utilizadas as plataformas do Portal Capes, Google Acadêmico e Scielo, a partir dos termos "contação de histórias", “educação infantil" e "literatura infantil". Após a leitura dos títulos dos artigos, foi observado que alguns deles se repetiram nas diferentes bases e outros não preenchiam os critérios deste estudo. Após esta primeira seleção os trabalhos foram identificados, lidos, e analisados quanto à consistência das informações e dos dados apresentados pelos autores. A segunda etapa consistiu na redação dos textos a partir das análises obtidas. 


\section{DISCUSSÕES DE RESULTADOS}

A partir da leitura foram organizadas as conclusões dos trabalhos pesquisados. Esse aspecto foi de fundamental importância para a presente pesquisa, pois, conforme descreve Gil (2010), “a citação das principais conclusões a que os outros autores chegaram permite salientar a contribuição da pesquisa realizada, que pode demostrar contradições ou reafirmar comportamentos e as atitudes".

Para melhor compreensão foram selecionados, na tabela abaixo, alguns artigos que embasaram o trabalho.

Quadro 1 - Artigos que embasaram a pesquisa

\begin{tabular}{|c|c|c|c|}
\hline \multicolumn{2}{|c|}{ Título e ano da publicação } & \multirow{2}{*}{$\begin{array}{l}\text { Autoria } \\
\\
\text { Ana do Nascimento } \\
\text { Mateus e outros. }\end{array}$} & \multirow{2}{*}{ 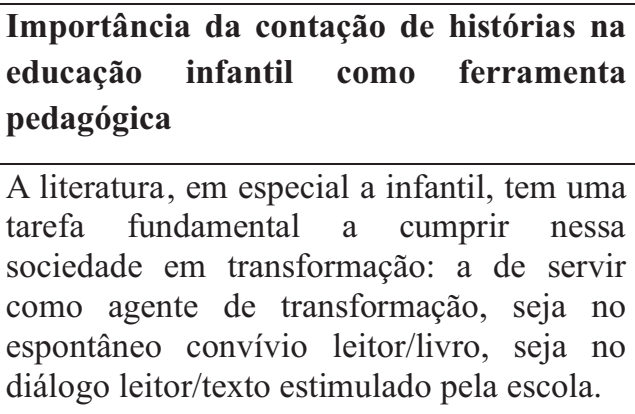 } \\
\hline Artigo 1 & $\begin{array}{l}\text { A importância de contar } \\
\text { história na educação } \\
\text { infantil. (2018) }\end{array}$ & & \\
\hline Artigo 2 & $\begin{array}{l}\text { A arte de contar histórias: } \\
\text { perspectivas teóricas e } \\
\text { práticas. (2012) }\end{array}$ & $\begin{array}{l}\text { Alessandra Nunes. } \\
\text { Elisiane André. }\end{array}$ & $\begin{array}{l}\text { A contação de histórias pode contribuir para } \\
\text { o processo de construção do conhecimento, } \\
\text { bem como a formação desse indivíduo } \\
\text { enquanto leitor crítico. }\end{array}$ \\
\hline Artigo 3 & $\begin{array}{llr}\begin{array}{l}\text { Contação } \\
\text { como }\end{array} & \text { de } & \text { história } \\
\text { estratégia } & \\
\text { pedagógica } & \text { na } & \text { educação } \\
\text { infantil } & \text { e } & \text { ensino } \\
\text { fundamental. } & (2011)\end{array}$ & $\begin{array}{l}\text { Linete Oliveira e } \\
\text { Andreza Dalla. }\end{array}$ & $\begin{array}{l}\text { As autoras defendem a contação de história } \\
\text { como atividade interativa e pedagógica } \\
\text { mediada pelo educador. Contribui para o } \\
\text { desenvolvimento a partir das interações e } \\
\text { vivências oportunizadas pelas histórias. }\end{array}$ \\
\hline Artigo 4 & $\begin{array}{l}\text { Recursos simbólicos e } \\
\text { imaginação no contexto } \\
\text { da contação de história. } \\
(2018)\end{array}$ & $\begin{array}{c}\text { Renata Magalhães e } \\
\text { Fabrícia Teixeira }\end{array}$ & $\begin{array}{l}\text { A contação de história utilizada como } \\
\text { ferramenta pedagógica proporciona } \\
\text { interação entre professor e crianças. }\end{array}$ \\
\hline Artigo 5 & $\begin{array}{l}\text { A contação de história } \\
\text { como ação educativa: } \\
\text { reflexões sob o viés da } \\
\text { teoria cognitiva da } \\
\text { aprendizagem. (2014) }\end{array}$ & Rossoni e Janaina C. & $\begin{array}{l}\text { Contação de história defendida como ação } \\
\text { educativa produtora de aprendizagem } \\
\text { significativa, pois proporciona uma } \\
\text { interação sócio-dialética, contribuindo com } \\
\text { o desenvolvimento cognitivo dos } \\
\text { estudantes. }\end{array}$ \\
\hline
\end{tabular}

Fonte: as autoras 
A leitura dos artigos selecionados indica que a contação de histórias na educação infantil pode ser utilizada como ferramenta pedagógica pelos educadores, como sugerido por Bussatto (2006). Ao fazermos uma síntese das conclusões apresentadas nos artigos, foi possível categorizar a argumentação em dois grupos ou categorias: aprendizagem e interação.

Dos cinco artigos pesquisados, três deles (2, 3 e 4) concluem que a contação de histórias utilizada como ferramenta pedagógica pode contribuir com as aprendizagens dos estudantes. Os artigos discutem que, dentre outras coisas, as crianças aprendem muito sobre o mundo, sobre o cotidiano e, pincipalmente, sobre a competência de leitura. Sobre isso, Abramovich (1997) nos diz que “[...] o escutar pode ser o início da aprendizagem para se tornar leitor".

Quanto à interação, os artigos 1 e 4 indicam que a contação de histórias na educação infantil ajuda no processo de interação e diálogo das crianças com o professor (artigo 4), com o próprio livro, com seus sentimentos e com tudo o que se pode descobrir a partir das histórias (artigo 1). É possível observar nos estudos de Abramovich (1997) que a contação de histórias abre um leque de possibilidades no processo pedagógico:

[...] É também contando histórias que preparamos a criança para vivenciar com mais segurança suas próprias dificuldades ou encontrar um caminho para sua resolução. É através delas que se pode sentir e viver importantes emoções como: a raiva, a tristeza, alegria, tranquilidade e tantas outras, e viver profundamente tudo o que as narrativas provocam em quem as ouve. (ABRAMOVICH, 1997, p. 17).

Outro aspecto importante analisado em todos os artigos lidos foi em relação à importância do professor como mediador nas histórias contadas. Esse momento deve ser bem aproveitado, mas é preciso que o professor esteja empenhado em mergulhar na narração para que tenha uma arte com criatividade e beleza, podendo então investigar a imaginação das crianças, trazer a oralidade quando houver interação com a história, reconhecer a percepção dos alunos ao recontarem as histórias, assim compreendendo o que cada criança assimilou da história contada.

Estes professores devem respeitar os saberes adquiridos pelas crianças em cada história contada, estimulando-as na superação através do exercício da curiosidade, que estimula a imaginação e a observação. A criança tem paixão inata pela descoberta e por isso é fundamental alimentar-lhe a curiosidade, motivá-la a descobrir as saídas e orientá-las na investigação até conseguir o que deseja. 
Também é muito importante que o professor trabalhe a interdisciplinaridade que já está nos Referenciais Curriculares Nacionais para a Educação Infantil. Esse documento reúne objetivos, conteúdos e orientações didáticas e nele consta que a partir da história podem ser trabalhados temas de diferentes disciplinas, fugindo do modo tradicional e despertando maior interesse dos alunos pelo tema.

\section{CONSIDERACÕES FINAIS}

Esta pesquisa teve como objetivo compreender e apresentar, a partir dos estudos analisados, que a contação de histórias na educação infantil é um instrumento poderoso que possibilita diversas maneiras na prática educativa. Segundo vários estudos, a contação de histórias ajuda no desenvolvimento de várias aprendizagens que se relacionam diretamente com o desenvolvimento cognitivo e com o processo de interação das crianças no cotidiano.

O estudo exposto discorreu sobre a contação de histórias que para a criança é um momento mágico. Esse envolvimento passa a ser tarefa de todos os profissionais na áre a de educação infantil no cenário da sala de aula ou em outro ambiente selecionado, pois favorece o aprendizado da criança. Segundo vários autores pesquisados, é na infância o começo das bases fundamentais na formação da personalidade no envolvimento social e efetivo da criança. É necessário, no período inicial de sua vida, contar com o auxílio dos professores, pois os mesmos fazem parte desta jornada.

Este tema proporcionou muitos conhecimentos e, após a leitura da pesquisa, é possível concluir que a contação de histórias é uma forma de incentivo para os professores exercerem com muito mais criatividade os momentos que estiverem com as crianças. Não só o lúdico das histórias contadas, mas a união, o respeito e a participação do grupo. A contação de histórias pode agir também como um instrumento mediador em sala de aula onde o professor absorve a atividade como valiosa prática pedagógica.

O estudo deste tema deve servir para que outros pesquisadores continuem seus trabalhos e ampliem seus conhecimentos, trazendo novas abordagens sobre a contação de histórias. A importância do tema abre um leque para os professores da área de educação infantil porque completa com satisfação o cotidiano da escola, favorecendo o dia a dia dos professores em sua rotina pedagógica. 


\section{REFERÊNCIAS}

ABRAMOVICH, Fani. Literatura infantil: gostosuras e bobices. São Paulo: Scipione, 1997.

MATEUS, Ana do Nascimento B. et al. A importância de contar histórias na educação infantil. Minas Gerais: 2018. Curso de Pedagogia da PUC Minas. Disponível em: periodicos.pucminas.br/index.php/article/download. Acesso em: 10 abr. 2020.

ALESSANDRA, Nunes Elisiane André. A arte de contar histórias: perspectivas, teorias e práticas vivenciais: Revistas eletrônica da UR1 Revista eletrônica de extensão da URI, p. 20 /ISSN-1809/1636.

BUSATTO, Cléo. A arte de contar histórias no século XXI: Tradição e Ciber. Petrópolis: Vozes, 2006.

O livro infantil e a forma do leitor. Petrópolis: Vozes, 1995.

BRASIL. Ministério da Educação e do Desporto. Secretaria de Ed. Fund. Referencial Curricular. Nacional para Ed. Inf. Brasília: Mec. / Sef. 1998 Vol. 3.

BRASIL. Lei n. 9.394, de 20 de dezembro de 1996. Estabelece as Diretrizes e Bases da Educação Nacional. Brasília-DF,1996.

CANÁRIO, Rui. A escola tem futuro? Das promessas às incertezas. Porto Alegre: Artmed, 2006.

COELHO, Nelly Novais. Literatura Infantil: Teoria, Análise, Didática. São Paulo: Moderna, 2000.

. Contar histórias uma Arte sem idade. São Paulo: Ed. Ática, 1999.

. Contar histórias: uma arte sem idade. São Paulo: Ática, 2001.

COELHO, Betty. Contar Histórias: Uma Arte Sem Idade. São Paulo: Ática, 1986.

CURY, Augusto Jorge. Pais brilhantes e professores fascinantes. Rio de Janeiro: Editora Sextante, 2003.

CUNHA, Maria Antunes. Literatura infantil: teoria e prática, 100 ed. São Paulo: Ática, 1990.

DEMO, P. Educar pela Pesquisa. Campinas/SP: Ed. Autores Associados, 1996.

FARIAS, Francy Rennia Aguiar de. Literatura Infantil: A Contribuição dos Contos de Fadas para a Construção do Imaginário Infantil, 2012. Disponível em: 
http://www.facsaoroque.br/novo/publicacoes/pdf/v3-n1-2012/Francy.pdf . Acesso em: 13 de abr. 2020.

FRANTZ, Maria Helena Zancan. O ensino da literatura nas séries iniciais. Ijuí: Ed. UNIJUÍ, 1997.

FLECK, Beatriz Varges. Literatura Infantil. Florianópolis: UDESC/CEAD, 2003.82 (Caderno Pedagógico).

GIL, Antônio Carlos. Métodos e técnicas de pesquisa social. São Paulo: Atlas, 2008.

JOSETE, Jolibert. Formando crianças leitoras. Porto Alegre: editora Artes Médicas ,1994.

KUHLMANN JR., M. Educação infantil e currículo. In: FARIA, A. L. G.; PALHARES, M. S. (Orgs.). Educação infantil pós-LDB: rumos e desafios. Campinas: Autores Associados, 1999.

KRAMER, S. (Org.). Formação de profissionais de educação infantil no Estado do Rio de Janeiro. Relatório de Pesquisa. Rio de Janeiro: Ravil, 2001.

LINETE, Oliveira-Andreza Dalla. Contação de história como estratégia pedagógica na educação infantil e ensino Fundamental. Educare ET/educare -revista de educação. Vol. 6. julho/dez. 2011.

OLIVEIRA, Cristiane Madaleno de. Livro e Infância. Disponível em: http://www.graudez.com.br/ lit. inf./livros.htm. Acesso em: 06 abr. de 2020.

PATRINI, Maria de Lourdes. A renovação do conto: emergência de uma prática oral. São Paulo: Cortês, 2005.

RENATA, Magalhaes Fabrícia Teixeira. Recursos Simbólicos e imaginação no da contação de história Psicologia escolar. SP. v. 22 jan/abr de 2018. Universidade de Brasília-DF, Brasil.

RODRIGUES, Edvânia Braz Teixeira. Cultura, Arte e Contação de Histórias. Goiânia: Universidade Federal de Goiás. 2005.

ROSSONI, Janaina C. A contação de história como ação educativa: Reflexões sob o viés da teoria cognitiva da aprendizagem. Atos de pesquisa em Educação. PPGE/ME/ISSN1809-0354. V.9,534, $2^{\text {a }}$ ed. mai/ago. 2014. 